\title{
Efficacy of a brief multifactorial adherence- based intervention in reducing blood pressure: a randomized clinical trial
}

This article was published in the following Dove Press journal:

Patient Preference and Adherence

5 December 2014

Number of times this article has been viewed

\author{
Alfonso Leiva' \\ Antonio Aguiló ${ }^{2}$ \\ Marta Fajó-Pascual ${ }^{3}$ \\ Lucia Moreno ${ }^{4}$ \\ Ma Carmen Martín ${ }^{5}$ \\ Elena Marina Garcia ${ }^{6}$ \\ Rosa Elena Duro ${ }^{7}$ \\ Francisca Serra ${ }^{8}$ \\ Pilar Dagosto 9 \\ Ana Aurelia Iglesias-Iglesias ${ }^{10}$ \\ Rosa Maria Company"l \\ Aina Yañez ${ }^{12}$ \\ Joan Llobera' ${ }^{13}$ \\ On behalf of The Adherence Group \\ 'Primary Care Research Unit of \\ Mallorca, Baleares Health Services- \\ IbSalut, Mallorca, ${ }^{2}$ Research Group \\ on Evidence, Lifestyles and Health, \\ Universitat Illes Balears, Palma, \\ ${ }^{3}$ Faculty of Health and Sport Sciences, \\ University of Zaragoza, Huesca, ${ }^{4}$ Son \\ Cladera Health Centre, Baleares Health \\ Services-IbSalut, Mallorca, ${ }^{5}$ Actur Sur \\ Health Centre, Aragon Health Services- \\ Salud, Aragón, Zaragoza, ' ${ }^{6}$ Coll D'en \\ Rabassa Health Centre, Baleares Health \\ Services-IbSalut, Mallorca, ${ }^{7}$ San Agustín \\ Health Centre, Baleares Health Services- \\ IbSalut, Mallorca, ${ }^{8}$ Santa María Health \\ Centre, Baleares Health Services-lbSalut, \\ Mallorca, ${ }^{9}$ Sineu Health Centre, Baleares \\ Health Services-IbSalut, Mallorca, ${ }^{\circ}$ Santa \\ Ponça Health Centre, Baleares Health \\ Services-lbSalut, Mallorca, "'Department \\ of Pharmacy, Manacor Hospital-Llevant \\ Sector, Baleares Health Services-lbSalut, \\ Mallorca ${ }^{12}$ Montuiri Health Centre, \\ Baleares Health Services-IbSalut, \\ Mallorca, ${ }^{13}$ Fundació d'Investigació \\ Sanitaria Illes Balears (FISIB), Son \\ Espases Hospital, Baleares Health \\ Services-IbSalut, Mallorca, Spain
}

Correspondence: Alfonso Leiva Primary Care Research Unit of Mallorca, Baleares Health Services-lbSalut, C/Reina Esclaramunda n9, Cp:0700, Mallorca, Spain Email aleiva@ibsalut.caib.es
Background: Lowering blood pressure (BP) by antihypertensive (AHT) drugs reduces the risks of cardiovascular events, stroke, and total mortality. However, poor adherence to AHT medications reduces their effectiveness and increases the risk of adverse events.

Objective: To evaluate the effectiveness of a multifactorial adherence-based intervention in a primary care setting in lowering BP.

Methods/design: Multicenter parallel randomized controlled trial. Thirty two nurses in 28 primary care centers of three Spanish regions. Patients aged 18-80 years, taking AHT drugs with uncontrolled BP $(\mathrm{n}=221)$ were randomized to a control group (usual care) or a multifactorial adherence-based intervention including nurse-led motivational interviews, pill reminders, family support, BP self-recording, and simplification of the dosing regimen by a pharmacist.

Main outcome measures: The primary outcome was 12-month blinded measure of systolic BP (mean of three measurements). The secondary outcomes were 12-month diastolic BP and proportion of patients with adequately controlled BP.

Results: One hundred and fourteen patients were allocated to the intervention group and 109 to the control group. At 12 months, 212 (89\%) participants completed the study. The systolic BP in the intervention group was 151.3 versus 153.7 in the control group $(P=0.294)$. The diastolic BP did not differ between groups (83.4 versus 83.6). Of the patients in the control group, $9.2 \%$ achieved BP control versus a $15.8 \%$ in the intervention group. The relative risk for achieving BP control was 1.72 (95\% confidence interval: 0.83-3.56).

Conclusion: A multifactorial intervention based on improving adherence in patients with uncontrolled hypertension failed to find evidence of effectiveness in lowering systolic BP.

Trial registration: ISRCTN21229328.

Keywords: hypertension, medication adherence, blood pressure, intervention studies

\section{Introduction}

The overall prevalence of hypertension among adults is about $35 \%$, since the prevalence of hypertension increases with age, from $40 \%$ of middle-aged individuals and up to $68 \%$ of elderly individuals. ${ }^{1-3}$ It is a growing public health problem in Western countries with aging populations. ${ }^{4}$ Most population-based studies confirm that hypertension increases the risk for cardiovascular events. ${ }^{5}$ Antihypertensive (AHT) agents can effectively lower blood pressure (BP) and significantly reduce the rates of stroke, coronary heart disease, cardiovascular death, and total mortality by $30 \%-40 \%$, $20 \%-21 \%, 26 \%-28 \%$, and $13 \%-16 \%$, respectively. ${ }^{6}$

Hypertension, however, remains difficult to control, with BP control achieved by only $40 \%$ of hypertensive patients in primary care. ${ }^{7}$ The failure of physicians to 
intensify therapy (clinical inertia) and low adherence by patients to medication are considered the major modifiable causes of poor BP control. ${ }^{8,9}$ Adherence can be defined as the extent to which patients follow the instructions they are given for prescribed treatments. About 30\%-50\% of patients show low adherence to AHT, ${ }^{10,11}$ and poor adherence is associated with higher BP. ${ }^{12}$

A report by the World Health Organization, addressing the general importance of improving adherence to longterm medical treatments, found that adherence resulted from complex interactions among the social environment, patients, and health care professionals. ${ }^{13}$ Low adherence has also been reported to increase the cost of treating hypertension by $15 \%-20 \%$, and to be associated with more frequent hospitalization, use of emergency services, and admission to intensive care. ${ }^{14}$

Low adherence to long-term treatment often occurs when the treatment is complex or when the disease is asymptomatic. Low adherence to AHT reduces drug effectiveness and increases the risk of cardiovascular morbidities. Conversely, adherence to AHT has been reported to reduce the risk of hospitalization by about $50 \%$ and to reduce mortality rates. ${ }^{15,16}$

Several factors have been reported associated with poor adherence to AHT, including patient perception that the disease is not significant, forgetfulness, the occurrence of adverse drug effects, lack of treatment effectiveness, and the patient's poor or incomplete knowledge of the disease. ${ }^{17,18}$ Most of these factors related to non-adherence, however, are modifiable and previous trials have shown that several strategies are effective in improving adherence to AHT. ${ }^{19}$ However, most clinical trials failed to evidence improvements in lowering BP.

The aim of the study was to evaluate the effectiveness of a multifactorial intervention based on a nurse-led motivational interview, simplification of dosing regimen by a pharmacist, reminder packaging, social and family support, and BP selfmeasurement intervention in reducing systolic and diastolic $\mathrm{BP}$ in patients with elevated BP.

\section{Methods and design Study design}

This study was a two arm, parallel, multicenter, randomized controlled trial performed in three regions of Spain (the Balearic Islands, Aragon, and Catalonia) between February 2011 and September 2013. The study was approved by the Research Ethics Committee of the Balearic Islands (Mallorca, Spain). The study design, procedures and reporting followed the CONSORT statement recommendations on randomized controlled trials. ${ }^{20}$

\section{Participants and randomization}

Participating nurses were selected from 28 primary care centers. Patients aged 18-80 years with uncontrolled essential hypertension, as defined by European Societies of Hypertension and Cardiology (ESH/ESC) guidelines ${ }^{21}$ (ie, systolic $\mathrm{BP} \geq 140 \mathrm{mmHg}$ and/or average diastolic $\mathrm{BP} \geq 90 \mathrm{mmHg}$ in patients without diabetes type II or renal failure, or $\geq 130 / 80 \mathrm{mmHg}$ for patients with diabetes type II or renal failure, on two consecutive visits 2 weeks apart), and attending a nurse consultation, were deemed eligible. Patients with non-essential hypertension; those undergoing hemodialysis; institutionalized or terminally ill patients; and those unwilling to provide informed consent were excluded. Patients were enrolled in the study from February 2011 to August 2012.

Randomization and allocation concealment were centralized at a single coordinating center, using a computer generated allocation sequence with a block size of eight. Once participants had provided verbal and written informed consent, they were randomized to either the intervention or the control group.

\section{Sample size}

Sample size was calculated based on an expected mean difference of $6 \mathrm{mmHg}$ and a standard deviation (SD) of $15 \mathrm{mmHg}$. The calculation was also based on a conservative assumption of $15 \%$ contamination in the control group and loss to follow-up of $20 \%$ of patients. Based on these calculations, we planned to enroll 320 patients.

\section{Blinding}

Due to study procedures, patients and nurses could not be blinded to the patient allocation. The main outcome was assessed by an external nurse not involved in the study and blinded to patient allocation. The statistician and the physicians treating the patients were also blinded to patient allocation.

\section{Multifactorial intervention}

The intervention consisted of five components delivered during three interventional visits: (1) A motivational interview based on the Health Belief Model ${ }^{22}$ was designed to explore non-adherence to AHT treatment, to resolve ambivalences that patients had regarding medication, and to explore perceptions that patients had about their ability to control events 
(locus of control). (2) Pillbox reminder: a 7-day pillbox organizer was provided to each patient and its use explained. (3) Family support: each patient was allowed to designate one person in his/her household who would be responsible for reminding the patient to take medication and would monitor medication intake. The designated person was required to accept responsibility for these tasks. (4) BP measurements and AHT reminder forms: each patient was provided 12 forms (one per month) to record the date, hour, and results of all BP measurements. AHT dosage and a telephone contact number were recorded on each form. This information was frequently updated. (5) Simplification of dosing regimen: AHT treatment was recorded at the baseline visit. A pharmacist supervised each patient's dosage and treatment and, when possible, simplified the dosing regimen at the first follow-up visit.

The first follow-up visit took place after 1 month and consisted of a motivational interview (25 minutes), simplification of dosing regimen, and instructions on a pill reminder ( 5 minutes), self-recording of BP ( 5 minutes), and family support ( 5 minutes). The second and third visits took place after 3 and 9 months, respectively, each consisting of a motivational interview (25 minutes), check of self-recorded $\mathrm{BP}$ (5 minutes), and family support ( 5 minutes).

\section{Control group}

Patients randomized to the control group did not receive any change in their care. However, they were contacted at baseline and at 12 months and asked to complete the same measurements and interviews as the intervention group.

\section{Data collection and management}

Patients in both groups had two baseline visits 1 week apart and before study initiation to ensure that they met study criteria. Data were obtained at the second baseline visit and at 12-month follow-up from patient interviews and reviews of primary care records.

Parameters recorded at baseline included BP, age, sex, weight, height, marital status, social class, level of education, hypertension duration, number of AHT drugs taken, adherence to AHT treatment, cardiovascular risk factors, target organ damage, cardiovascular diseases, nephropathy, and cardiovascular risk. BP, adherence to AHT treatment, and changes in AHT medication were recorded at 12 months.

Social class was assessed according to the guidelines of the Spanish National Occupational Classification 2011. ${ }^{23}$ Duration of hypertension was calculated from the year of diagnosis in primary care records; patients with grade III or severe hypertension were defined as those with $\mathrm{BP} \geq 180 / 110 \mathrm{mmHg}$, as determined by European Guidelines.

Patient adherence to medication at baseline was assessed retrospectively by determining medication refills and medication possession ratio during the previous 6 months of a randomly chosen AHT drug. The medication possession ratio was defined as the number of days' supply of medication dispensed divided by the number of days evaluated.

Hypercholesterolemia was defined as a total cholesterol concentration $\geq 250 \mathrm{mg} / \mathrm{dL}$, a low-density lipoproteincholesterol concentration $\geq 155 \mathrm{mg} / \mathrm{dL}$ or a high-density lipoprotein-cholesterol concentration $<40 \mathrm{mg} / \mathrm{dL}$ in men and $<48 \mathrm{mg} / \mathrm{dL}$ in women or treatment with lipid-lowering drugs. Diabetes mellitus type II was defined as a fasting plasma glucose concentration $\geq 126 \mathrm{mg} / \mathrm{dL}$, a 2-hour-post-load plasma glucose concentration $\geq 200 \mathrm{mg} / \mathrm{dL}$, or treatment with AHA agents. Smoking was defined as currently smoking cigarettes and obesity as a body mass index $\geq 30 \mathrm{~kg} / \mathrm{m}^{2}$. A family history of premature cardiovascular disease was defined as a male or female first-degree relative experiencing a cardiovascular event before age 55 or 65 years, respectively.

Microalbuminuria and elevated serum creatinine concentrations were considered surrogates for target organ damage. Microalbuminuria was defined as urinary excretion of 30-300 $\mathrm{mg} / \mathrm{dL}$ albumin and elevated serum creatinine as a concentration of $1.3-1.5 \mathrm{mg} / \mathrm{dL}$ in men and $1.2-1.4 \mathrm{mg} / \mathrm{dL}$ in women. Patients were also assessed for nephropathy and left ventricular hypertrophy as detected in a positive echocardiogram.

A history of cardiovascular disease included stroke, ischemic heart disease, and/or congestive heart failure.

The REGICOR tables are the calibration of Framingham's equation in a Spanish population. These tables estimate the risks of coronary morbidity and mortality in individuals aged 35-74 years, differentiate diabetic from non-diabetic patients and include measures of high-density lipoprotein-cholesterol concentration. ${ }^{24}$

Changes in AHT medication at 12 months were determined by reviewing each patient's electronic drug recorder. The total number of changes included changes in dosage and active drugs. Patient adherence to medication was based on the medication possession ratio during the 6 months prior to enrollment and the final visit.

\section{Primary and secondary outcomes}

The primary outcome measure was systolic BP at 12 months. $\mathrm{BP}$ was measured according to ESH/ESC guidelines using an OMROM $705 \mathrm{CP}$ automated sphygmomanometer with a 
printer. Final data at 12 months were collected by independent research personnel not involved in the performance of the trial and blinded to patient allocation.

\section{Secondary outcome measures}

Secondary outcomes included diastolic BP at 12 months and proportion of participants with adequate BP control at 12 months according to ESH/ESC guidelines.

\section{Statistical analysis}

Outcomes were analyzed on an intention-to-treat basis. Categorical variables were reported as numbers and percentages and continuous variables as medians and interquartile ranges. Categorical baseline variables were compared using Fisher's exact test or the chi-squared test. Continuous baseline variables were compared using Student's $t$-test.

The unadjusted effectiveness of the intervention was estimated using Student's $t$-test. Since clinical inertia may be an important confounder for the effect of the intervention, the protocol included adjustments for changes in AHT treatment during the study. The total number of changes in treatment was assessed at follow-up and the effectiveness of the intervention was adjusted by means of a generalized linear model based on the normal distribution of the primary outcome and the identity link function.

Relative risks (RR) were calculated based on the proportion of patients in the intervention group with BP control. The absolute risk reduction and number needed to treat were also calculated from the RR.

There were no relevant missing data (Figure 1), with only 14 of $223(6.6 \%)$ patients missing the final evaluation. Based on an intention-to-treat analysis, these 14 patients were assigned a basal BP at 12 months.

Statistical significance was set at 5\%. Stata version 11.0 (StataCorp, College Station, TX, USA) was used for analyses.

\section{Results}

\section{Patient characteristics}

Table 1 shows that patient characteristics at baseline were similar in the two groups. Overall, mean patient age was 65 years $(\mathrm{SD}=10.7$ years), $56 \%$ were men and $75.8 \%$ were

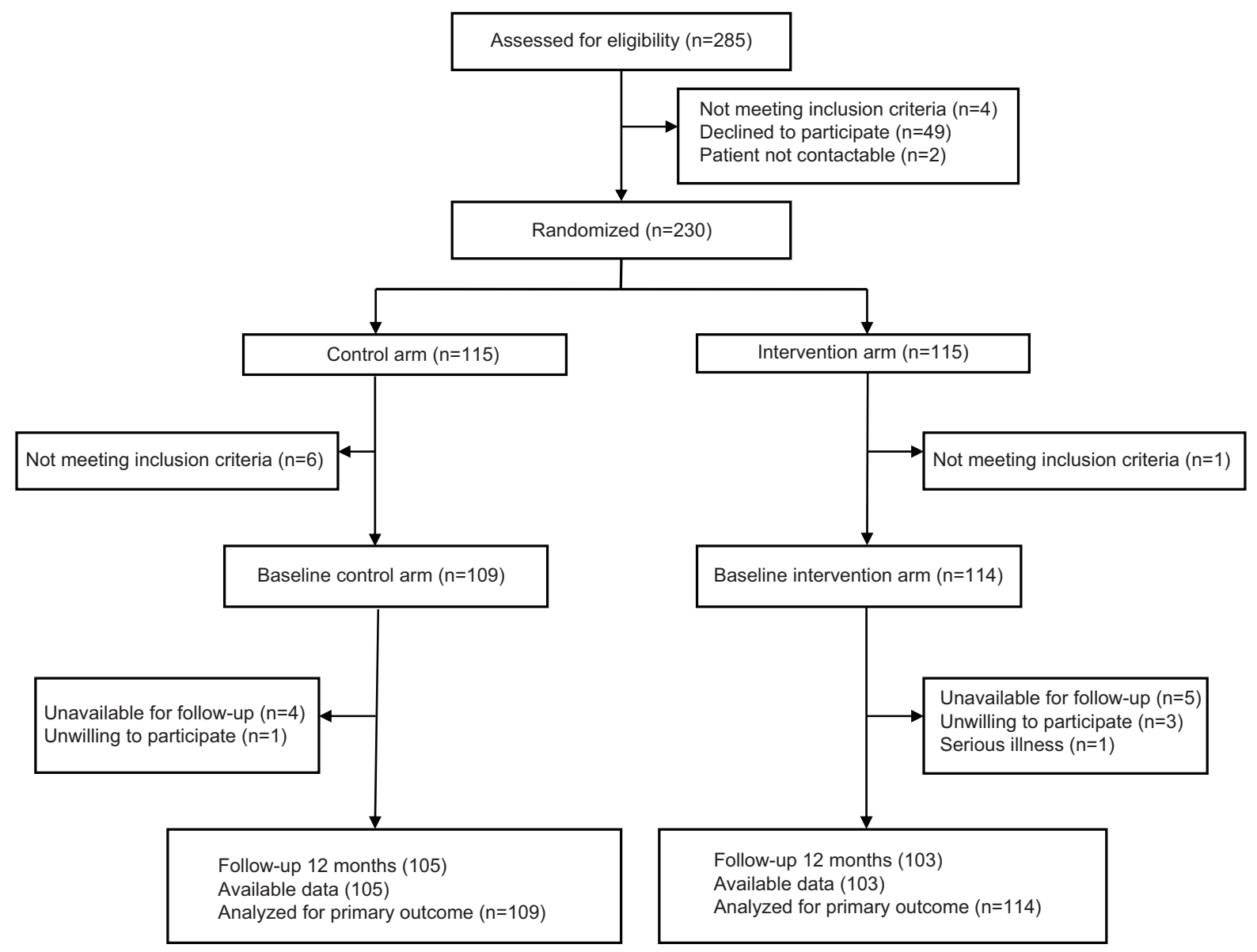

Figure I Trial profile. 
Table I Baseline demographic and clinical characteristics in the control and intervention groups

\begin{tabular}{|c|c|c|c|}
\hline Baseline characteristics & Control group n/N (\%) & Intervention group $\mathbf{n} / \mathbf{N}(\%)$ & $P$-value \\
\hline Age* & $66.7 \pm 11.7$ & $64.5 \pm 9.8$ & 0.145 \\
\hline Men & $55 / 102(53.9)$ & $62 / 105(59.0)$ & 0.485 \\
\hline \multicolumn{4}{|l|}{ Marital status } \\
\hline Married/cohabiting & $61 / 101(60.4)$ & $67 / 105(63.8)$ & \\
\hline Single/divorced/widowed & $40 / 101(39.6)$ & $38 / 105(36.2)$ & 0.667 \\
\hline \multicolumn{4}{|l|}{ Level of education } \\
\hline None & $23 / 107$ (2I.5) & $21 / 114(18.4)$ & \\
\hline Elementary school & $58 / 107(54.2)$ & $62 / 114(54.4)$ & \\
\hline Middle or high school & $17 / 107$ (15.9) & $18 / 114(15.8)$ & \\
\hline University studies & $9 / 107(8.4)$ & |3/| | 4 (II.4) & 0.859 \\
\hline \multicolumn{4}{|l|}{ Social class } \\
\hline Class I-II & $3 / 76(3.9)$ & $3 / 81$ (3.7) & \\
\hline Class III & $53 / 76(69.7)$ & $64 / 81(79.0)$ & \\
\hline Class IV-V & $20 / 76(26.3)$ & $|4 / 8|(17.3)$ & 0.380 \\
\hline $\mathrm{SBP}, \mathrm{mmH} \mathrm{g}^{*}$ & $155.5 \pm 13.4$ & $156.3 \pm 15.1$ & 0.697 \\
\hline $\mathrm{DBP}, \mathrm{mmH} \mathrm{g}^{*}$ & $83.6 \pm 10.3$ & $84.7 \pm 10.7$ & 0.436 \\
\hline Baseline heart rate, bpm* & $75.1 \pm 13.5$ & $76.0 \pm 14.5$ & 0.645 \\
\hline Severe hypertension & $4 / 104(3.8)$ & $7 / 105$ (6.7) & 0.361 \\
\hline Hypertension duration (years)* & $7.0 \pm 5.9$ & $6.3 \pm 6.2$ & 0.517 \\
\hline No of AHT drugs at baseline* & $2.3 \pm 1.1$ & $2.3 \pm 1.2$ & 0.754 \\
\hline Baseline adherence to $\mathrm{AHT}$ treatment* & $76.49 \pm 30.9$ & $75.14 \pm 26.2$ & 0.789 \\
\hline \multicolumn{4}{|l|}{ Cardiovascular risk factors } \\
\hline Cigarette smoking & $16 / 104(15.4)$ & $21 / 105(20)$ & 0.532 \\
\hline Hypercholesterolemia & $57 / 104(54.8)$ & $61 / 105(58.1)$ & 0.632 \\
\hline Diabetes mellitus & $48 / 104(46.2)$ & $53 / 105(50.5)$ & 0.532 \\
\hline Obesity (BMI >30 kg/m²) & $52 / 104(50)$ & $62 / 105(59)$ & 0.189 \\
\hline Family history of premature CHD & $5 / 104(4.8)$ & $8 / 105(7.6)$ & 0.400 \\
\hline \multicolumn{4}{|l|}{ Target organ damage } \\
\hline Left ventricular hypertrophy & $0 / 104(0)$ & $3 / 105(2.4)$ & 0.08 \\
\hline Microalbuminuria & $4 / 104(3.8)$ & $2 / 105(1.9)$ & 0.401 \\
\hline Elevated serum creatinine & $5 / 104(4.8)$ & $4 / 105(3.8)$ & 0.722 \\
\hline Nephropathy & $9 / 105(8.6)$ & $5 / 104(4.8)$ & 0.260 \\
\hline \multicolumn{4}{|l|}{ Cardiovascular diseases } \\
\hline Stroke & $3 / 104(2.9)$ & $2 / 105$ (1.9) & 0.643 \\
\hline Ischemic heart disease & $5 / 104(4.8)$ & $9 / 105(8.6)$ & 0.276 \\
\hline Congestive heart failure & $5 / 104(4.8)$ & $6 / 105(5.7)$ & 0.769 \\
\hline REGICOR cardiovascular risk & $1.46(0.6)$ & $1.52(0.74)$ & 0.582 \\
\hline
\end{tabular}

Note: *Data are expressed as mean \pm standard deviation.

Abbreviations: $n$, sample; N, population; BMI, body mass index; CHD, cardiovascular disease; SBP, systolic blood pressure; DBP, diastolic blood pressure; AHT, antihypertensive; REGICOR, Registre Gironí del cor.

adherent to medication. The median number of risk factors was 2 (interquartile range: $1-3$ ), the mean duration of hypertension was 7 years ( $\mathrm{SD}=6$ years), and 20 patients were diagnosed with hypertension the year before enrollment. The median number of AHT drugs per patient was 2 (interquartile range: $1-3$ ), with $26.9 \%$ of patients receiving one agent. Of the $73.1 \%$ of patients taking $\geq 2$ drugs, $70 \%$ were taking fixeddose combinations in a single pill. Angiotensin-converting enzyme inhibitors (ACEI; 19.3\%), diuretics (14.7\%), and calcium channel blockers (CCB; 14.1\%) were the drugs most frequently prescribed as monotherapy, followed by beta-blockers $(11.3 \%)$, angiotensin II receptor antagonists (ARBII) (10.5\%), and alpha-blockers (3.6\%). In combination, the drugs most frequently prescribed were an ARBII plus a diuretic (12.9\%); an ACEI plus a diuretic (6.4\%); an ACEI plus a $\mathrm{CCB}(4.9 \%)$; an ARBII, a diuretic, plus a $\mathrm{CCB}(0.8 \%)$; and an ACEI, a CCB plus a diuretic (0.3\%).

The REGICOR Score is used to estimate risk in individuals aged 35-75 years; since 36 patients (17\%) were over 75-years old, their REGICOR Score could not be determined. The mean risk of cardiovascular disease at 10 years was $1.5 \%(\mathrm{SD}=0.7 \%)$.

The application of the different components of the multifactorial intervention varied widely. Dose regimens were simplified in six patients $(5.7 \%) ; 70$ patients $(66.7 \%)$ participated in all three motivational sessions; pill reminders were provided to 46 patients (43.8\%); filled BP measurement forms were submitted by 55 patients $(52.4 \%)$ each at visits 
one and two, and by 33 patients $(31.4 \%)$ at visit three; and 51 patients $(48.6 \%)$ designated a person to remind them and supervise adherence to treatment.

Adherence to AHT medication at 12 months was $76 \%$, $75.3 \%$ in the intervention group, and $76.7 \%$ in the control group. At 12 months, $51.4 \%$ in the intervention group versus $50.8 \%$ in the control group were below $80 \%$ adherence.

\section{Outcomes}

\section{Primary outcome}

Efficacy results are shown in Table 2. Systolic BP at 12 months was similar in the intervention and control groups (151.3 $\mathrm{mmHg}$ versus $153.7 \mathrm{mmHg}, P=0.294$ ), as were the reductions from baseline ( $5 \mathrm{mmHg}$ versus $2.1 \mathrm{mmHg}$ ).

\section{Secondary outcomes}

Diastolic BP at 12 months was similar in the intervention and control groups (83.4 $\mathrm{mmHg}$ versus $83.6 \mathrm{mmHg}$ ), as was the percentage in each group who achieved BP control according to ESC/ESH guidelines (15.8\% [18/114] versus 9.2\% [10/109], $P=0.098)$. Relative to the control group, the RR of achieving BP control in the intervention group was 1.72 (95\% confidence interval [CI]: $0.83-3.56)$, with a RR reduction of -0.72 (95\% CI: -2.56 to 0.17$)$ and an absolute risk reduction of $-0.07 \%$ ( $95 \% \mathrm{CI}:-0.15 \%$ to $0.02 \%)$. Consequently, 15 patients would have to receive the proposed interventions for 1 year for one patient to achieve BP control when compared with patients receiving usual care.

\section{Conclusion}

The main finding of our study was that a multifactorial intervention based on improving treatment adherence in a primary care setting did not lead to the expected improvement in BP. Similar to previous findings, we found that adherence to treatment tends to be poorer in populations with poorly controlled BP. ${ }^{25}$ Moreover, patient adherence to medication varied greatly when treatment was supervised by the medical staff, ${ }^{26}$ with the percentage of patients adherent at the end of follow-up varying from $53.2 \%-94.5 \%$. This wide adherence variability may be due to the characteristics of nurses and the method of delivery of the intervention. Our results suggest that differences in the application of the intervention and overestimation of its effects may have resulted in the absence of statistically significant differences between our intervention and control groups. Alternatively, few treatments were able to be simplified, since most of the patients were taking two or three drugs at enrollment, with most taking medications once per day. Indeed, only six patients experienced changes in medication over the 12-month study period.

Our findings are nevertheless consistent with previous results. ${ }^{27-30}$ For example, a study of hypertensive patients with diabetes type II and kidney disease testing a multifactorial intervention that included self-BP monitoring, a revision of the medication, telephone calls, and motivational interviews, found that this intervention did not significantly improve systolic or diastolic BP. A pilot study testing the ability of behavioral feedback to improve medication adherence in older adults with hypertension found that this intervention improved adherence, but not systolic BP. Similarly, motivational interviews in African-American patients improved adherence, but not systolic BP, and simplification of AHT regimens was also ineffective. In contrast, the Com99 ${ }^{31}$ trial, which tested a brief adherence-based intervention in a large number of patients, found that the intervention significantly reduced systolic $\mathrm{BP}$, by a mean $2 \mathrm{mmHg}$, compared with a control group.

Clinical inertia is one of the most important modifiable factors related to lack of BP control. Moreover, changes in AHT regimens have been associated with improvements in systolic and diastolic BP. Our study hypothesized that clinical inertia could be an important confounder, especially if general practitioners (GPs) overseeing patients in the intervention group were more prone to change AHT treatment than GPs of control patients. Thus, to minimize the possibility of differential effects between groups, GPs

Table 2 Blood pressure measures in the control and intervention groups at 12 months

\begin{tabular}{|c|c|c|c|c|c|c|}
\hline \multirow[t]{3}{*}{ Efficacy } & \multicolumn{6}{|l|}{12 months } \\
\hline & \multicolumn{3}{|c|}{ Unadjusted analysis } & \multicolumn{3}{|c|}{ Adjusted analysis" } \\
\hline & Control & Intervention & $P$-value & Control & Intervention & $P$-value \\
\hline SBP, mmHg, mean (SD) & $153.7(16.8)$ & $151.3(17.8)$ & 0.294 & $153.8(0.70)$ & I5I.3 (0.54) & 0.290 \\
\hline $\mathrm{DBP}, \mathrm{mmHg}$, mean (SD) & $83.6(11.4)$ & $83.4(I I . I)$ & 0.917 & $83.6(0.7 I)$ & $83.5(0.62)$ & 0.901 \\
\hline$\Delta \mathrm{SBP}, \mathrm{mmHg}$, mean $(\mathrm{SD})^{*}$ & $-2.1(16.8)$ & $-5(18.3)$ & 0.208 & $-2.1(1.58)$ & $-5.1(I .7 I)$ & 0.219 \\
\hline$\triangle \mathrm{DBP}, \mathrm{mmHg}$, mean $(\mathrm{SD})^{*}$ & $-0.1(9.1)$ & $-1.2(9.1)$ & 0.405 & $-0.16(0.43)$ & $-1.19(0.47)$ & 0.515 \\
\hline
\end{tabular}

Note: ${ }^{\# A d j u s t e d ~ f o r ~ c h a n g e s ~ i n ~ A H T ~ m e d i c a t i o n ~ o v e r ~ t i m e . ~}{ }^{*} \Delta$ represent changes in SBP and DBP between the baseline value and the 12 months value. Abbreviations: SBP, systolic blood pressure; DBP, diastolic blood pressure; SD, standard deviation; AHT, antihypertensive. 
were blinded to patient allocation, and all changes in AHT regimens were registered in both groups. After adjusting for changes in treatment, the adjusted and unadjusted results did not significantly differ.

The strength of this study is the use of a methodology designed to minimize the confounding effect of clinical inertia. The trial design showed great external validity, since only 14 patients were lost to follow-up and both adherence to medication and systolic BP were measured objectively and in a blinded manner.

This study had several limitations. Similar to most behavioral interventions, blinding is often difficult to achieve due to the nature of these interventions. However, efforts were made to determine the final outcome measurements and the allocation of patients to the GPs in a blinded manner. Although our study design included a specific feature to prevent Hawthorne effects (ie, preventing or hampering control patients from attending follow-up visits), ${ }^{32}$ we cannot exclude the possibility that the level of care in the control group was positively influenced by participation in the trial.

\section{Ethical approval}

The study protocol was approved by the Primary Care Research Committee and Mallorca Ethical Committee of Clinical Research (IB 969/08 PI).

\section{The Adherence Group}

Mallorca: Elisa Miró, Coll d'en Rabassa Health Centre; Antonia Pocoví, Sant jordi Health Centre, M. Antonia Perello, Sa cabaneta Health Centre; Margarita Cerdà Alcudia Health Centre; Aina Fiol, Arenal Health Centre; Alicia Esther Tur, Santa Ponça Health Centre; Laura Martin, Cala Ratjada Health Centre; Cristina Alvarez-Ossorio, Camp Redò Health Centre; Margarita Planas, Emili Darder Health Centre; Dolores Calderón, Inca Health Centre; Francisca Fullana, Son Macià Health Centre; Francisca Salvà, Pere Garau Health Centre; Catalina Pascual, Son Servera Health Centre.

Toledo: Rosa Ma Gómez-Calcerrada Silleria Health Centre; $\mathrm{M}^{\mathrm{a}}$ Amor Ortiz Silleria Health Centre.

\section{Funding}

The Adherencia study was funded by the Carlos III Health Institute of the Ministry of Economy and Competitiveness of Spain (contract No PS09/01456). The Ministry had no role in the design or conduct of the study; the collection, management, analysis, or interpretation of the data; or the preparation, review, and approval of the manuscript or the decision to submit for publication.
This study was also supported by the Health Promotion and Preventive Activities - Primary Health Care Network, sustained by the Ministry of Health ISCIII-RETCI G03/170 and RD06/0018.

\section{Acknowledgment}

We are particularly grateful to Fernando Rigo for reading and revising the study protocol.

\section{Disclosure}

All authors declare: support from the Carlos III Health Institute, Ministry of Economy and Competitiveness; no financial relationship over the previous 3 years with any organization that may have an interest in the submitted work; no other relationships or activities that could appear to have influenced the submitted work.

\section{References}

1. Banegas JR, Rodríguez-Artalejo F. The problem of arterial hypertension in Spain. Rev Clin Esp. 2002;202(1):12-15.

2. Banegas JR, Rodríguez-Artalejo F, Ruilope LM, et al. Hypertension magnitude and management in the elderly population of Spain. $J$ Hypertens. 2002;20:2157-2164.

3. RigoCF,FronteraJG,LloberaCJ,RodriguezRT, Borras BI,Fuentespina VE. [Prevalence of cardiovascular risk factors in the Balearic Islands (CORSAIB Study)]. Rev Esp Cardiol. 2005;58:1411-1419.

4. Kearney PM, Whelton M, Reynolds K, Muntner P, Whelton PK, He J. Global burden of hypertension: analysis of worldwide data. Lancet. 2005;365:217-223.

5. Prospective Studies Collaboration. Age-specific relevance of usual blood pressure to vascular mortality: a meta-analysis of individual data for one million adults in 61 prospective studies. Lancet. 2002;360:1903-1913.

6. Neal B, MacMahon S, Chapman N; Blood Pressure Lowering Treatment Trialists' Collaboration. Effects of ACE inhibitors, calcium antagonists, and other blood-pressure-lowering drugs: results of prospectively designed overviews of randomised trials. Blood Pressure Lowering Treatment Trialists' Collaboration. Lancet. 2000;356(9246):1955-1964.

7. Coca A. [Evolución del control de la hipertensión arterial en atención primaria en España. Resultados del estudio Controlpres 2003]. Hipertensión. 2005;22:5-14. Spanish.

8. Phillips LS, Branch WT, Cook CB, et al. Clinical inertia. Ann Intern Med. 2001;135:825-834.

9. Sharkness CM, Snow DA. The patient's view of hypertension and compliance. Am J Prev Med. 1992;8:141-146.

10. Márquez Contreras E, Gil Guillén V, Casado Martínez JJ, et al. Analysis of studies published on hypertension treatment non-compliance in Spain between 1984 and 2005. Aten Primaria. 2006;38(6):325-332.

11. Psaty B, Koepsell T, Wagner E, LoGerfo J, Inui T. The relative risk of incident coronary heart disease associated with recently stopping the use of beta-blockers. JAMA. 1990;263(12):1653-1657.

12. Márquez Contreras E, Casado Martínez JJ, Martínez Vázquez M, et al. Análisis de la influencia del cumplimiento terapéutico farmacológico, en las presiones arteriales y grado de control de la HTA, mediante monitorización ambulatoria de la PA. Med Clin (Barc). 2001; 116(Supl 2):114-121. Spanish.

13. Sabate E. Adherence to Long-Term Therapies: Evidence for Action. Geneva: World Health Organization; 2003. 
14. Sokol MC, McGuigan KA, Verbrugge RR, Epstein RS. Impact of medication adherence on hospitalization risk and healthcare cost. Med Care. 2005;43:521-530.

15. Rasmussen JN, Chong A, Alter DA. Relationship between adherence to evidence-based pharmacotherapy and long-term mortality after acute myocardial infarction. JAMA. 2007;297(2):177-186.

16. Mazzaglia G, Ambrosioni E, Alacqua M, et al. Adherence to antihypertensive medications and cardiovascular morbidity among newly diagnosed hypertensive patients. Circulation. 2009;120(16): $1598-1605$.

17. Haynes RB. A critical review of the "determinants" of patient compliance with therapeutic regimens. In: Sackett DL, Haynes RB, editors. Compliance with Therapeutic Regimens. Baltimore: Johns Hopkins University Press; 1976.

18. Norman SA, Marconi KM, Schezel GW, Schechter CF, Stolley PD. Beliefs, social normative influences, and compliance with antihypertensive medication. Am J Prev Med. 1985;1:10-17.

19. Schroeder K, Fahey T, Ebrahim S. Interventions for improving adherence to treatment in patients with high blood pressure in ambulatory settings. Cochrane Database Syst Rev. 2004;(2):CD004804.

20. Schulz KF, Altman DG, Moher D. CONSORT 2010 statement: updated guidelines for reporting parallel group randomised trials. BMJ. 2010;340:c332.

21. Mancia G, De Backer G, Dominiczak A, et al. 2007 ESH-ESC practice guidelines for the management of arterial hypertension: ESH-ESC task force on the management of arterial hypertension. J Hypertens. 2007; 25:1751-1762.

22. Becker M. The health belief model and personal health behaviour. Health Educ Monogr. 1974;2:4.

23. Domingo-Salvany A, Bacigalupe A, Carrasco JM, Espelt A, Ferrando J, Borrell C. [Proposals for social class classification based on the Spanish National Classification of Occupations 2011 using neo-Weberian and neo-Marxist approaches]. Gac Sanit. 2013;27:263-272.
24. Marrugat J, Vila J, Baena-Diez JM, et al. [Relative validity of the 10 -year cardiovascular risk estimate in a population cohort of the REGICOR study]. Rev Esp Cardiol. 2011;64:385-394.

25. Hill MN, Miller NH, Degeest S, et al. Adherence and persistence with taking medication to control high blood pressure. J Am Soc Hypertens. 2011;5:56-63.

26. Sencan NM, Wertheimer A, Levine CB. What determines the duration of patient medication compliance in patients with chronic disease: are we looking in the wrong place? South Med Rev. 2011;4:97-101.

27. Williams A, Manias E, Walker R, Gorelik A. A multifactorial intervention to improve blood pressure control in co-existing diabetes and kidney disease: a feasibility randomized controlled trial. J Adv Nurs. 2012;68:2515-2525.

28. Ruppar TM. Randomized pilot study of a behavioral feedback intervention to improve medication adherence in older adults with hypertension. J Cardiovasc Nurs. 2010;25:470-479.

29. Ogedegbe G, Chaplin W, Schoenthaler A, et al. A practice-based trial of motivational interviewing and adherence in hypertensive African Americans. Am J Hypertens. 2008;21:1137-1143.

30. Dresser GK, Nelson SA, Mahon JL, et al. Simplified therapeutic intervention to control hypertension and hypercholesterolemia: a cluster randomized controlled trial (STITCH2). J Hypertens. 2013;31: 1702-1713.

31. Pladevall M, Brotons C, Gabriel R, et al. Multicenter cluster-randomized trial of a multifactorial intervention to improve antihypertensive medication adherence and blood pressure control among patients at high cardiovascular risk (the COM99 study). Circulation. 2010;122:1183-1191.

32. McCarney R, Warner J, Iliffe S, van Haselen R, Griffin M, Fisher P. The Hawthorne Effect: a randomised, controlled trial. BMC Med Res Methodol. 2007;7:30.
Patient Preference and Adherence

\section{Publish your work in this journal}

Patient Preference and Adherence is an international, peer-reviewed, open access journal that focuses on the growing importance of patient preference and adherence throughout the therapeutic continuum. Patient satisfaction, acceptability, quality of life, compliance, persistence and their role in developing new therapeutic modalities and compounds to optimize

\section{Dovepress}

clinical outcomes for existing disease states are major areas of interest for the journal. This journal has been accepted for indexing on PubMed Central. The manuscript management system is completely online and includes a very quick and fair peer-review system, which is all easy to use. Visit http://www. dovepress.com/testimonials.php to read real quotes from published authors. 